\title{
Stability Indicating Reverse Phase Chromatographic Method for Estimation of Related Substances in Voriconazole Drug Substance by Ultra Performance Liquid Chromatography
}

Maheswara Reddy Musirike*, Hussain Reddy K and Useni Reddy Mallu

Department of Chemistry Sri Krishnadevaraya University, Ananthapur, India

\begin{abstract}
A simple, sensitive and accurate analytical method for related substances of Voriconazole has been developed and validated by using RP-UPLC technique. The developed analytical procedure was validated as per $\mathrm{ICH}$ recommendations. Analysis was performed on a HALO C18 $(100 \times 2.12 .7 \mu)$ column. $20 \mathrm{mM}$ ammonium formate adjusted the $\mathrm{pH}$ to 4.5 with formic acid was selected as buffer. Acetonitrile was used as organic modifier in the mobile phase composition. A simple gradient was applied in the method. Flow rate of mobile phase was kept at $0.4 \mathrm{ml}$ per min. Column compartment temperature was maintained at $45^{\circ} \mathrm{C}$. Injection volume was set at $1 \mu \mathrm{L}$ with an auto sampler maintained the temperature at $10^{\circ} \mathrm{C}$. Detection of all the components was monitored at $254 \mathrm{~nm}$ by photodiode array detector. Developed method satisfies the system suitability criteria, peak integrity, and resolution for the parent drug and its related substances. The proposed method was validated for Specificity, precision, accuracy, linearity, limit of detection and quantification. Forced degradation studies were conducted to assess stability indicating nature of the method under acidic, basic, oxidative and photolytic conditions. Run time less than 7.0 minutes indicating that the method is cost effective and productive; it can be successfully applied for testing of related substances in drug substance and assay of drug substance in routine quality control analysis and stability testing.
\end{abstract}

Keywords: Voriconazole; Ultra performance liquid chromatography; Fungal infections; Related substances, Method development and validation

\section{Introduction}

Voriconazole is a second-generation triazole antifungal agent, designated chemically as (2R,3S)-2-(2,4- difluorophenyl)-3-(5-fluoro4-pyrimidinyl)-1-(1H-1,2,4-triazol-1-yl)- 2-butanol. Voriconazole has been widely used for the treatment of invasive fungal diseases, particularly invasive aspergillosis. In addition, voriconazole is also approved for the treatment of invasive candidosis, as well as for less frequent fungal infections such as fusariosis and scedosporiosis. Its fungicidal action is due to inhibition of fungal cytochrome P450dependent $14 \alpha$-sterol demethylase, a key enzyme of ergosterol biosynthesis. Inhibition of ergosterol biosynthetic pathway leads to a disruption of the integrity and the function of the fungal membrane.

As per the literature Voriconazole estimation was done by chiral capillary electrophoresis method [1] and HPTLC [2] methods. For the determination of voriconazole concentrations in the biological fluids, the main methods presently used are high-performance liquid chromatographic techniques coupled with mass spectrometry [3-9]. High performance liquid chromatographic techniques coupled with ultraviolet spectroscopy were proposed for estimation voriconazole concentration in human plasma [10-14].

Since this drug is being marketed in domestic and international market the present investigation by the author was to develop a rapid, accurate and precise RP-UPLC method [15-17] for the determination of related substances. The objective was to develop a cost effective ultra fast reverse phase UPLC method for estimation of related substances in Voriconazole, the developed method was validated as per regulatory guidelines and successfully transferred to quality control lab. The innovative approach of using stationary phase with sub $2 \mu$ particles [18-21] provides a comprehensive combination of selectivity and speed. The validation parameters $[22,23]$ provide valuable information on precision accuracy, limit of detection, limit of quantification and linearity of related substances. The method was subjected to validation according to ICH requirements [24,25].

Figure 1 represents chemical structures of Voriconazole and its four related substances.

\section{Materials and Methods}

\section{Instrumentation and reagents}

The Waters ultra performance liquid chromatograph equipped with photodiode array detector. The output signal was monitored and processed using the Empower software. Acetonitrile was purchased from Rankem. MilliQ purification system was used to get HPLC grade water. Analytical column was a $100-\mathrm{mm} \times 2.1-\mathrm{mm}$ Halo C18 (advanced materials technology) with $5-\mu \mathrm{m}$ spherical particles. Test samples and reference standards of Voriconazole were donated by Apotex India pvt ltd.

\section{Chromatographic conditions}

Mobile phase consists of $20 \mathrm{mM}$ ammonium formate buffer and $\mathrm{pH}$ of the solution was adjusted to 4.5 with formic acid. The chromatographic separation was achieved on a Halo C18, $100 \times 2.1$

*Corresponding author: Maheswara Reddy Musirike, Department of Chemistry Sri Krishnadevaraya University, Ananthapur, Andhra Pradesh- 515003, India, Tel: 085542 55700; E-mail: musirikemahesh@gmail.com

Received November 25, 2015; Accepted January 22, 2016; Published January 25, 2016

Citation: Musirike MR, Reddy KH, Mallu UR (2016) Stability Indicating Reverse Phase Chromatographic Method for Estimation of Related Substances in Voriconazole Drug Substance by Ultra Performance Liquid Chromatography. Pharm Anal Acta 7: 460. doi:10.4172/2153-2435.1000460

Copyright: (c) 2016 Musirike MR, et al. This is an open-access article distributed under the terms of the Creative Commons Attribution License, which permits unrestricted use, distribution, and reproduction in any medium, provided the original author and source are credited. 
<smiles>O=C(Cn1cncn1)c1ccc(F)cc1F</smiles>

1-(2,4-Difluorophenyl)-2-(1,2,4-triazol-1-yl)ethanone (a) Voriconazole impurity A (b) Voriconazole impurity B (Process/Degradation impurity) (Process impurity)

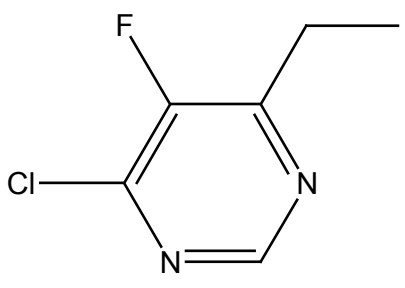

4-Chloro-6-ethyl-5-fluoropyrimidine

(c) Voriconazole impurity C (d) Voriconazole impurity D (Process/Degradation impurity) (Process impurity)

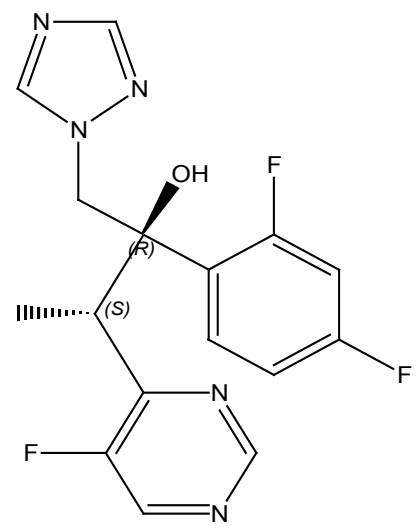

(2R,3S) -2- (2, 4- difluorophenyl)-3-(5-fluoro-4-pyrimidinyl)1-(1H-1, 2, 4-triazol-1-yl)-2-butanol

(e) Voriconazole

Figure 1: Chemical structures of Voriconazole and its related substances. mm $2.7 \mu \mathrm{m}$ Column. HPLC grade acetonitrile was used as organic modifier. Mobile phase flow rate was kept at $0.4 \mathrm{~mL} / \mathrm{min}$. Gradient program was set as Time/ \% of solution B: 0/10, 1/20, 1.5/40, 4/50, $5 / 70,5.5 / 10,7 / 10$. Column temperature was maintained at $45^{\circ} \mathrm{C}$ and detection was carried at $254 \mathrm{~nm}$. Sample compartment was maintained at $10^{\circ} \mathrm{C}$ with an injection volume of $1 \mu \mathrm{L}$.

\section{Preparation of standard and sample}

A mixture of standard solution was prepared by weighing Voriconazole and its related compounds to yield a final concentration $0.10 \%$ each of Voriconazole, Impurity A, Impurity B, Impurity C and Impurity D with respect to the test sample concentration of $0.5 \mathrm{mg} /$ $\mathrm{ml}$. Buffer and acetonitrile in the ratio 8:2 was used as the diluent for preparation of sample and standard solution.

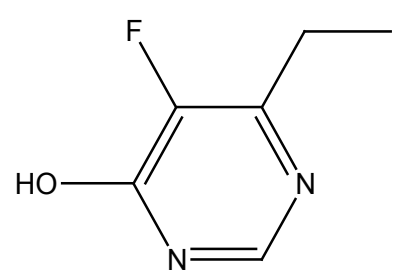

6-Ethyl-5-fluoropyrimidin-4-ol

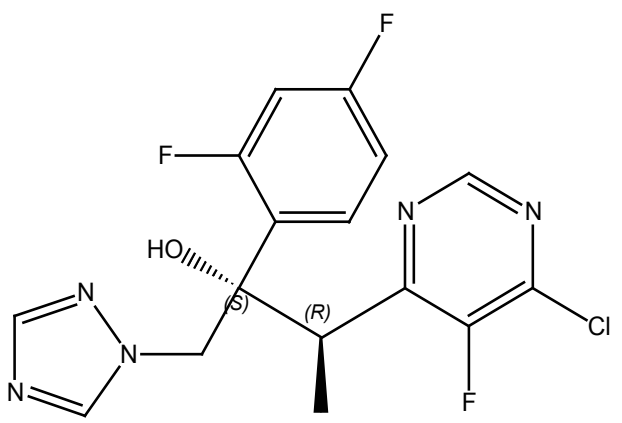

$\left.\right|_{\mathrm{Cl}} ^{\mathrm{H}}$

, 3S/2S, 3R)-3-(4-chloro-5-fluoropyrimidin-6-yl)-2-(2, 4-difluorophenyl)-1-(1H-1, 2, 4triazol-1-yl)butan-2-ol Hydrochloride

\section{System suitability}

A standard solution was injected on to the chromatographic system to ensure system suitability by verifying Retention times (RT), Peak Tailing factor (T), column efficiency (N) and resolution (R) for all related substances of Voriconazole. For confirmation of co- elution and interference of other impurities, peak purity testing was done.

Tailing factor should be not less than 0.9 and not more than 2.0. Plate count should be minimum 5000 and resolution should not be less than 2.0 among all the components. Peak purity evaluation should be done to evaluate homogeneity of peak.

\section{System precision}

Precision of the method was reported by injecting six replicates of 
standard solution consecutively under the same analytical conditions. Standard deviation and \% of residual standard deviations of all the components were reported. Intermediate precision of the method was also evaluated using different analyst, different day and different make of instrument in the same laboratory.

Report standard deviation and \% RSD of all the related substances and Voriconazole. \% RSD should not be more than 5.0\%.

\section{Limit of detection (LOD) and limit of quantification (LOQ)}

The Limit of detection and Limit of quantification for Voriconazole and its related substances were determined from linear regression plot. Residual standard deviation and slope of the standard solution were considered for calculation of LOQ and LOD. Precision, Linearity and Accuracy were proved at LOQ level.

Residual standard deviation multiplied with 10 and divided by slope can be used for calculation of quantification limit and residual standard deviation multiplied with 3 and divided by slope can be used for calculation of detection limit.

\section{Linearity}

Solutions for Linearity of related substances method was prepared by serially diluting the impurity stock solution to required concentration levels. The solutions were prepared at six different concentration levels ranging from LOQ to $160 \%$ with respect to specification limits. Calibration curve was drawn by plotting the peak response of related substances versus its corresponding concentrations.

Correlation coefficient of the calibration curve should not be less than 0.990, slope, intercept and relative response factors were established.

\section{Accuracy}

Voriconazole sample solution was spiked with impurity standard solutions at three concentration levels corresponding to LOQ, 100\% and $160 \%$ of impurity concentration. The $\%$ recovery of three levels was reported.

$\%$ Recovery was calculated based on amount of standard addition and amount of recovery in the test sample solution. \% Recovery should be not less than $80 \%$ and not more than $120 \%$.

\section{Specificity}

Demonstration of method specificity is to measure the analyte resolution in the presence of its potential impurities and degradants. The specificity of the developed RP-UPLC method was conducted in presence of sample diluent and its four potential impurities. Test samples were exposed to forced degradation studies under various acid, base, oxidative and photolytic conditions.

Test ample should be free of interferences from sample diluent and degradation impurities. Peak purity should be evaluated to assess homogeneity of peak under all the stress conditions.

\section{Results and Discussion}

\section{Method development and optimization}

The main objective of the chromatographic method development was to separate Voriconazole impurities from the main peak with an adequate resolution and symmetry. The initial method scouting started with an Isocratic mobile phase. It was observed that the impurity $\mathrm{C}$ is closely eluting with main peak in isocratic mode and also peak symmetry of impurities and voriconazole was poor. Adequate resolution and symmetrical peak shapes were achieved in gradient elution with a shorter run time. $20 \mathrm{mM}$ Ammonium formate was selected as a buffer by considering mass compatibility. The wavelength maximum for voriconazole and its related substances was in the range of 245-260 $\mathrm{nm}$. Selection of $254 \mathrm{~nm}$ as detection of all impurities provides good response. Resolution of all the related substances and symmetrical peaks were noticed in Halo C18 column when compared to Acquity $\mathrm{BEH}$ C18 column. Selection of acetonitrile as organic modifier provides stable baseline and eliminates interference from blank.

\section{System suitability}

All the related substances of voriconazole were eluted as per the retention given below. Adequate resolution was found between all the related substances. Voriconazole drug substance was found symmetric and well separated by its potential process impurities. A typical system suitability chromatogram of sample diluent, standard solution and test solution chromatograms are shown in Figure 2a-2c.

In the optimized conditions, Voriconazole and its related substances were well resolved with a resolution of more than 2.0. The tailing factor is in the range of 1.0-1.2 which indicates symmetry of peaks. Theoretical plates more than 10000 show the efficiency of the column. System suitability results are tabulated in Table 1 .

\section{System precision}

System precision was evaluated by performing six replicate injections of standard solution at specification level. The \% relative standard deviation of 6 injections was within the acceptable limit.

The obtained \% RSD results are in the range of 1.2-3.8 which indicates the precision of the instrument to proceed for analysis. Results are tabulated in Table 2.

\section{Limit of detection (LOD) and Limit of quantification (LOQ)}

Limit of detection (LOD) and limit of quantification (LOQ) of Voriconazole drug substance and its related substances were established from linear regression curve by measuring residual standard deviation and slope of the curve. Results are tabulated in Table 3. Sensitivity is the ability of method to detect and quantify the impurities present in the sample accurately.

Precision at LOQ level was determined for 6 consecutive injections and the obtained \% RSD was $4.8 \%$. Accuracy at LOQ level was in the range of 89 to $105.2 \%$. The obtained correlation coefficient of 0.999 from regression statistics declares linear relationship of the method.

\section{Linearity}

Linearity of the method was to establish a linear relationship of concentration over response. Solutions of Voriconazole and its related substances are prepared from LOQ level to $160 \%$ of the specification limit. The correlation coefficient obtained was greater than 0.99 . The regression statistics for Voriconazole drug substance and its related substances are tabulated in Table 4.

The obtained data stated that an excellent correlation was established between the peak response and concentration of the analyte and impurities. Relative response factor was also calculated to estimate the response factor of impurity against drug the response of substance to measure the accurate content of impurity present in the drug substance. Graphical representation of linear regression is shown in Figure 3. 


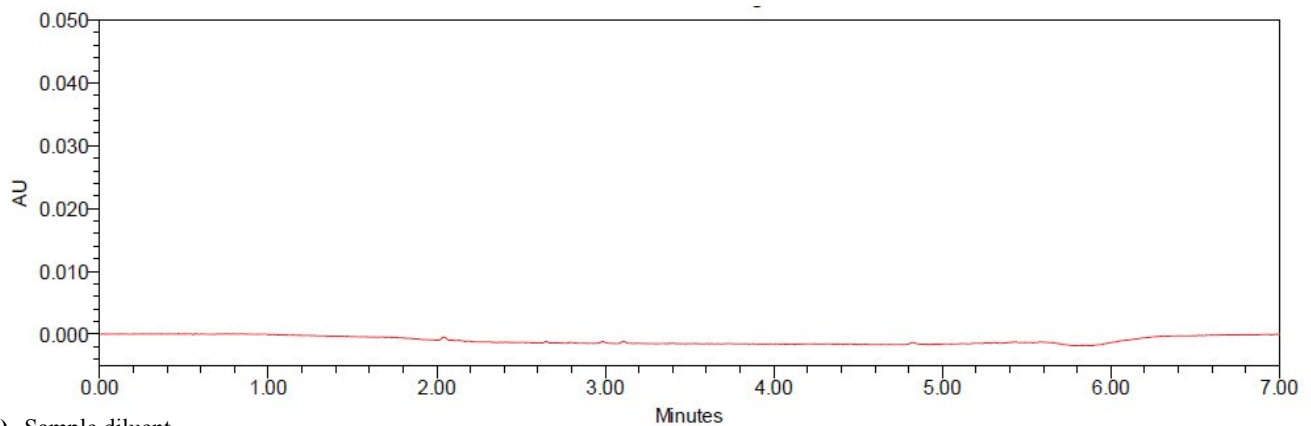

a) Sample diluent

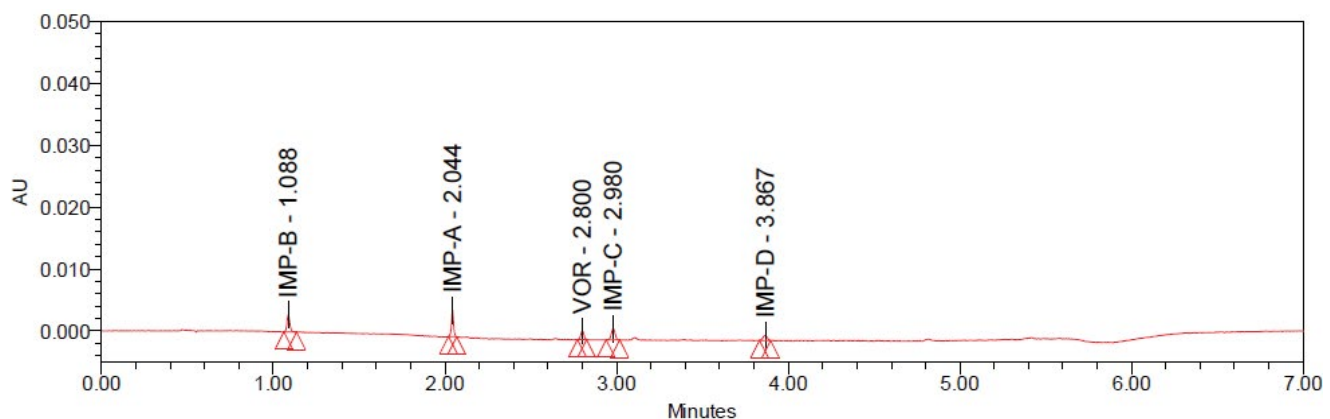

b) Standard solution

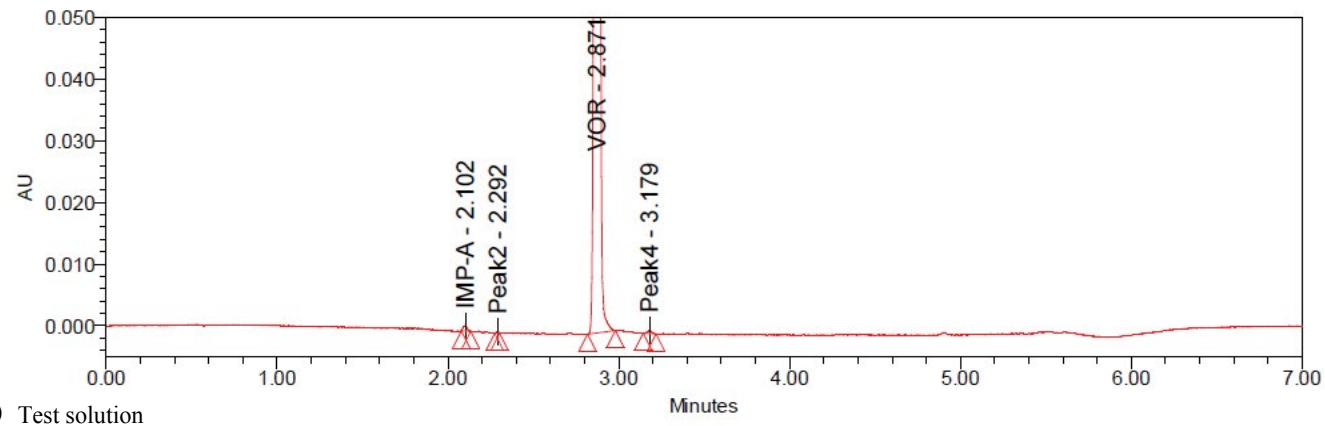

Figure 2: A typical chromatogram showing the Voriconazole (a) sample diluent (b) Standard solution.

\begin{tabular}{|c|c|c|c|c|c|c|}
\hline Component & RT (Min) & Resolution & Tailing factor & Plate count & Peak angle & Peak threshold \\
\hline Impurity B & 1.1 & - & 1.1 & 12500 & 2.4 & 6.1 \\
\hline Impurity A & 2.0 & 37.0 & 1.0 & 13339 & 5.0 & 5.3 \\
\hline Voriconazole & 2.8 & 26.1 & 1.1 & 45666 & 10.2 & 16 \\
\hline Impurity C & 3.0 & 4.7 & 1.2 & 125212 & 8.8 & 13.5 \\
\hline Impurity D & 3.9 & 19.6 & 1.1 & 113331 & 10.8 & 21.3 \\
\hline
\end{tabular}

Table 1: System suitability results.

\begin{tabular}{|c|c|c|c|c|c|}
\hline \multirow{2}{*}{ Injection } & \multicolumn{3}{|c|}{ Response } \\
\cline { 2 - 5 } & Voriconazole & Impurity A & Impurity B & Impurity C \\
\hline 1 & 1856 & 3750 & 3136 & 2767 \\
\hline 2 & 1811 & 3741 & 3037 & 2520 \\
\hline 3 & 1861 & 3671 & 2961 & 2544 \\
\hline 4 & 1803 & 3729 & 3096 & 2505 \\
\hline 5 & 1886 & 3797 & 3103 & 2630 \\
\hline 6 & 1811 & 3791 & 3020 & 2596 \\
\hline Mean & 1838 & 3746 & 3059 & 1350 \\
\hline STDEV & 34 & 46 & 65 & 1396 \\
\hline
\end{tabular}

Table 2: System precision results. 


\begin{tabular}{|c|c|c|c|c|}
\hline Inj.\# & Voriconazole & Impurity A & Impurity B & Impurity C \\
\hline LOQ $(\mu \mathrm{g} / \mathrm{ml})$ & 124 & 81.4 & 60.8 & 76.8 \\
\hline LOD $(\mu \mathrm{g} / \mathrm{ml})$ & 41 & 27.1 & 20.3 & 146.7 \\
\hline
\end{tabular}

LOQ-Limit of Quantitation; LOD-Limit of Detection

Table 3: Limit of quantitaion and detection.

\begin{tabular}{|c|c|c|c|c|c|c|c|c|c|c|}
\hline \multirow[b]{2}{*}{ Level } & \multicolumn{2}{|c|}{ Voriconazole } & \multicolumn{2}{|c|}{ Impurity A } & \multicolumn{2}{|c|}{ Impurity B } & \multicolumn{2}{|c|}{ Impurity C } & \multicolumn{2}{|c|}{ Impurity D } \\
\hline & $\begin{array}{l}\text { Conc. } \\
(\mu \mathrm{g} / \mathrm{mL})\end{array}$ & $\begin{array}{c}\text { Area } \\
\left(\mu V^{*} \text { sec }\right)\end{array}$ & $\begin{array}{l}\text { Conc. } \\
(\mu \mathrm{g} / \mathrm{mL})\end{array}$ & $\begin{array}{c}\text { Area } \\
\left(\mu \mathrm{V}^{*} \text { sec }\right)\end{array}$ & $\begin{array}{l}\text { Conc. } \\
(\mu \mathrm{g} / \mathrm{mL})\end{array}$ & $\begin{array}{c}\text { Area } \\
\left(\mu \mathrm{V}^{*} \text { sec }\right)\end{array}$ & $\begin{array}{l}\text { Conc. } \\
(\mu \mathrm{g} / \mathrm{mL})\end{array}$ & $\begin{array}{c}\text { Area } \\
\left(\mu \mathrm{V}^{*} \mathrm{sec}\right)\end{array}$ & $\begin{array}{l}\text { Conc. } \\
(\mu \mathrm{g} / \mathrm{mL})\end{array}$ & $\begin{array}{c}\text { Area } \\
\left(\mu \mathrm{V}^{*} \text { sec }\right)\end{array}$ \\
\hline LOQ & 123.6 & 350 & 81.3 & 460 & 60.8 & 220 & 76 & 210 & 146.7 & 246 \\
\hline $40 \%$ & 424 & 810 & 432 & 1780 & 428 & 1357 & 412 & 1190 & 436 & 695 \\
\hline $80 \%$ & 848 & 1498 & 864 & 3240 & 856 & 2565 & 824 & 2200 & 872 & 1295 \\
\hline $100 \%$ & 1060 & 1790 & 1080 & 3920 & 1070 & 3120 & 1030 & 2650 & 1090 & 1570 \\
\hline $120 \%$ & 1272 & 2096 & 1296 & 4640 & 1284 & 3750 & 1236 & 3190 & 1308 & 1820 \\
\hline $160 \%$ & 1696 & 2769 & 1728 & 5995 & 1712 & 4954 & 1648 & 4176 & 1744 & 2380 \\
\hline Slope & \multicolumn{2}{|c|}{1.5271} & \multicolumn{2}{|c|}{3.3493} & \multicolumn{2}{|c|}{2.8483} & \multicolumn{2}{|c|}{2.4975} & \multicolumn{2}{|c|}{1.3257} \\
\hline Intercept & \multicolumn{2}{|c|}{173.85} & \multicolumn{2}{|c|}{279.40} & \multicolumn{2}{|c|}{92.38} & \multicolumn{2}{|c|}{93.99} & \multicolumn{2}{|c|}{97.75} \\
\hline $\mathrm{R}$ & \multicolumn{2}{|c|}{0.9997} & \multicolumn{2}{|c|}{0.9994} & \multicolumn{2}{|c|}{0.9998} & \multicolumn{2}{|c|}{0.9993} & \multicolumn{2}{|c|}{0.9990} \\
\hline RRF & \multicolumn{2}{|c|}{1.00} & \multicolumn{2}{|c|}{2.19} & \multicolumn{2}{|c|}{1.87} & \multicolumn{2}{|c|}{1.64} & \multicolumn{2}{|c|}{0.87} \\
\hline
\end{tabular}

RRF-Relative Response factor, R- Correlation Coefficient

Table 4: Linearity results.

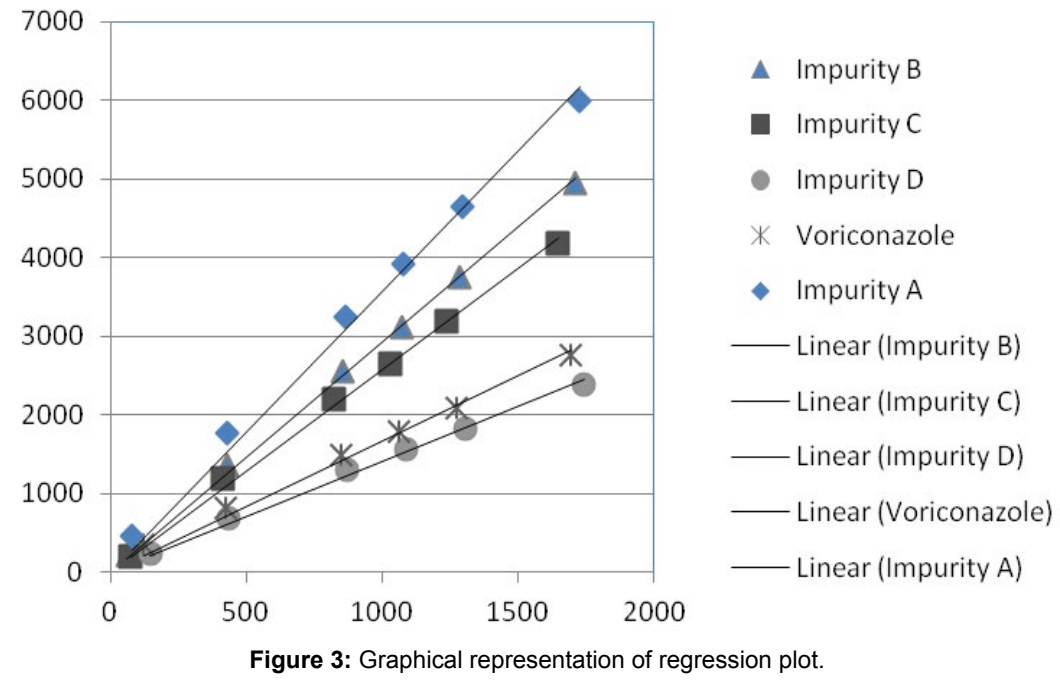

\section{Accuracy}

Accuracy of the method was determined by addition of known concentrations of standard solution to the test sample. The obtained recovery value indicates the trueness of the method to estimate impurities. Related substances of voriconazole spiked to the sample over a concentration range varying from QL to $160 \%$ of their respective target analyte concentrations. Acceptance criteria were in the range of $80 \%$ to $120 \%$.

The obtained percentage recovery value of related substances is in the range of $86.7 \%$ to $105.2 \%$ which declares the method accuracy. Accuracy results are reported in Table 5. A chromatogram of spiked sample is shown in Figure 4.

\section{Forced degradation studies}

Degradation studies were performed to demonstrate stability indicating nature of the method. Voriconazole test sample was exposed under various stress conditions like heat and humidity $\left(40^{\circ} \mathrm{C}\right.$ and $70 \%$ $\mathrm{RH}$ for 7 days), thermal $\left(60^{\circ} \mathrm{C}\right.$ for 7 days $)$ and photolytic conditions of fluorescent light $\left(1.2 \times 10^{6} \mathrm{LUX}\right.$ hours), UV light for a total exposure of $200 \mathrm{~W} \cdot \mathrm{hr} / \mathrm{m}^{2}$, acid hydrolysis $\left(1 \mathrm{~N} \mathrm{HCl} 80^{\circ} \mathrm{C}\right.$ for $\left.24 \mathrm{Hrs}\right)$, base hydrolysis $\left(0.1 \mathrm{~N} \mathrm{NaOH}, 80^{\circ} \mathrm{C}\right.$ for $\left.30 \mathrm{~min}\right)$ and oxidative stress. Testing of peak purity concludes the homogeneity and interference of unidentified impurities with peak of interest. The obtained peak purity value gives a clear indication of separation between stressed impurities with related substances of Voriconazole.

Sample prone to more degradation in basic and acidic conditions. Deschloro and Impurity A were observed in acid and basic hydrolysis conditions. A slight degradation was observed in heat and peroxide conditions. No degradation was observed in photolytic condition. Peak obtained in all the stress conditions was homogenous and unaffected by the presence of its degradation impurities, confirming the stability indicating nature of the method. Mass balance also established to 
Page 6 of 7

\begin{tabular}{|c|c|c|c|c|}
\hline S.NO & Accuracy Level & Impurity A & Impurity B & Impurity C \\
\hline 1 & LOQ & $105.2 \%$ & $96.1 \%$ & $89.0 \%$ \\
\hline 2 & $100 \%$ & $94.9 \%$ & $90.1 \%$ & $88.7 \%$ \\
\hline 3 & $160 \%$ & $86.7 \%$ & $93.2 \%$ & $100.0 \%$ \\
\hline
\end{tabular}

Table 5: Accuracy results.

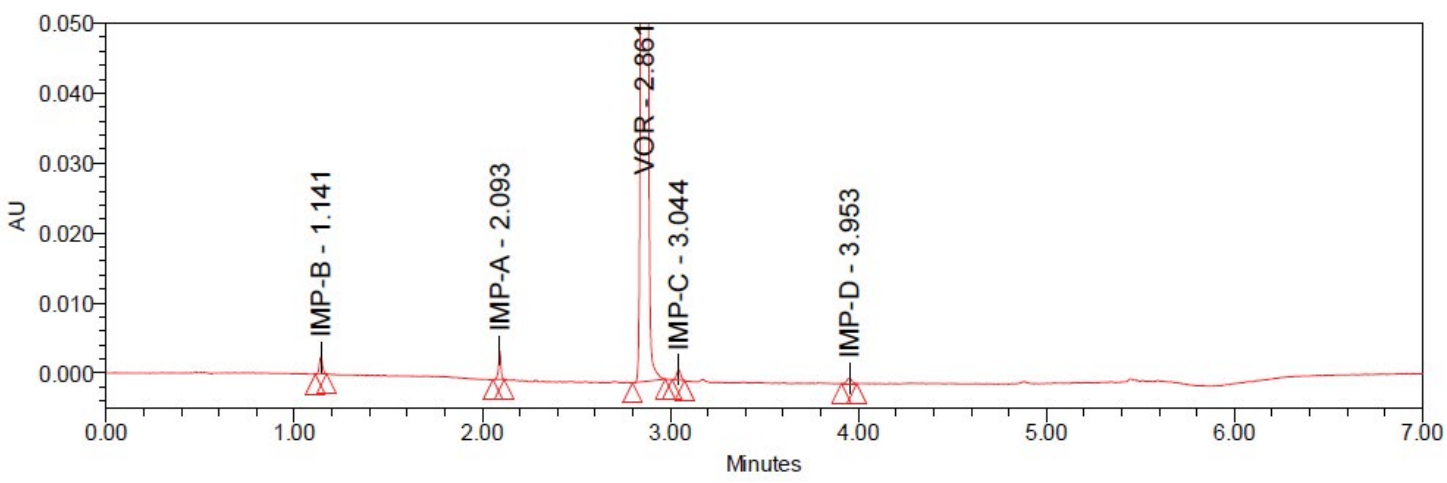

Figure 4: Test sample spiked with standard solution.

\begin{tabular}{|c|c|c|c|c|c|c|}
\hline Stress condition & Conc. $\mu \mathrm{g} / \mathrm{mL}$ & \%Degradation & Major degradant & Purity angle & Purity Threshold & Mass balance \\
\hline Non stressed & 512 & - & - & 0.10 & 2.2 & 100 \\
\hline Acid hydrolysis & 495 & $12.6 \%$ & Imp-A\&C & 0.15 & 2.45 & 99.2 \\
\hline Base hydrolysis & 502 & $18.1 \%$ & Imp-A\&C & 0.22 & 3.22 & 98.8 \\
\hline Oxidation & 515 & $3.2 \%$ & Imp-A & 0.25 & 2.66 & 99.1 \\
\hline Heat and humidity & 501 & No significant & 9.11 & 0.19 & 1.72 & 99.2 \\
\hline Photo stability & 511 & No significant & 8.22 & 0.26 & 3.55 & 99.4 \\
\hline Dry heat & 509 & $5.4 \%$ & Imp-A & 0.13 & 3.75 & 99.7 \\
\hline
\end{tabular}

Table 6: Forced degradation studies.

match up the sum of impurities with its assay value against reference unstressed sample. The results from forced degradation studies are summarized in Table 6

\section{Conclusion}

This paper describes a simple, accurate and reproducible fast Reverse phase-UPLC method for estimation of related substances in Voriconazole drug substance. Method validation was executed as per the guidelines recommended by ICH. Forced degradation studies were established to prove stability indicating nature of the method. The primary objective of the method was achieved by demonstrating that the method was cost effective, time effective and aiming towards green chemistry. The developed method was specific, precise, accurate and linear to estimate accurate amount of impurities present in the sample. Degradation studies confirmed the homogeneity and free of interferences with the peak of interest.

The method can be adopted to determine the related substances of drug substance in quality control labs. The same procedure can also be used to perform assay of drug substance.

\section{References}

1. Owens PK, Fell AF, Coleman MW, Berridge JC (1999) Separation of the voriconazole stereoisomers by capillary electrophoresis and liquid chromatography. Enantiomer 4: 79-90.

2. Khetre AB, Darekar RS, Sinha PK, Jeswani RM, Damle MC (2008) validated hptlc method for determination of voriconazole in bulk and pharmaceutical dosage form, Rasayan J Chem 1: 452-547

3. Zhou L, Glickman RD, Chen N, Sponsel WE, Graybill JR, et al. (2002)
Determination of voriconazole in aqueous humor by liquid chromatographyelectrospray ionization-mass spectrometry. J Chromatogr B Analyt Technol Biomed Life Sci 776: 213-220.

4. Keevil BG, Newman S, Lockhart S, Howard SJ, Moore CB, et al. (2004) Validation of an assay for voriconazole in serum samples using liquid chromatography-tandem mass spectrometry. Ther Drug Monit 26: 650-657.

5. Vogeser M, Schiel X, Spohrer U (2005) Quantification of voriconazole in plasma by liquid chromatography-tandem mass spectrometry. Clin Chem Lab Med 43: 730-734.

6. Baietto L, D'Avolio A, Ventimiglia G, De Rosa FG, Siccardi M, et al. (2010) Development, validation, and routine application of a high-performance liquid chromatography method coupled with a single mass detector for quantification of itraconazole, voriconazole, and posaconazole in human plasma. Antimicrob Agents Chemother 54: 3408-3413.

7. Verdier MC, Bentue-Ferrer D, Tribut O, Bellissant E (2010) Liquid chromatography-tandem mass spectrometry method for simultaneous quantification of four triazole antifungal agents in human plasma. Clin Chem Lab Med 48: 1515-1522.

8. Cheng Y, Zhang ZJ, Tian Y, Li WJ, Wei W (2011) Quantification of voriconazole in human plasma by high-performance liquid chromatography-electrospray ionization mass spectrometry: application to a bioequivalence study. Arzneimittelforschung 61: 132-139.

9. Couchman L, Buckner SL, Morgan PE, Ceesay MM, Pagliuca A, et al. (2012) An automated method for the simultaneous measurement of azole antifungal drugs in human plasma or serum using turbulent flow liquid chromatographytandem mass spectrometry. Anal Bioanal Chem 404: 513-523.

10. Chhun S, Rey E, Tran A, Lortholary O, Pons G, et al. (2007) Simultaneous quantification of voriconazole and posaconazole in human plasma by highperformance liquid chromatography with ultra-violet detection. J Chromatogr B Analyt Technol Biomed Life Sci 852: 223-228.

11. Gordien JB, Pigneux A, Vigouroux S, Tabrizi R, Accoceberry I, et al. (2009) 
Citation: Musirike MR, Reddy KH, Mallu UR (2016) Stability Indicating Reverse Phase Chromatographic Method for Estimation of Related Substances in Voriconazole Drug Substance by Ultra Performance Liquid Chromatography. Pharm Anal Acta 7: 460. doi:10.4172/2153-2435.1000460

Simultaneous determination of five systemic azoles in plasma by highperformance liquid chromatography with ultraviolet detection. J Pharm Biomed Anal 50: 932-938.

12. Dewani MC, Borole TC, Gandhi SP, Madgulkar AR, Damle MC (2011) Determination of voriconazole in human plasma by high performance liquid chromatographic with ultraviolet detection. International Journal of Research in Pharmaceutical and Biomedical Sciences 2: 1367-1373.

13. Pennick GJ, Clark M, Sutton DA, Rinaldi MG (2003) Development and validation of a high-performance liquid chromatography assay for voriconazole. Antimicrob Agents Chemother 47: 2348-2350.

14. Eiden C, Mathieu O, Peyrière H, Dominique H, Cociglio M (2008) Simultaneous quantification of voriconazole and its $\mathrm{N}$-oxide metabolite in human plasma by an easy and rapid isocratic LC method with UV detection. Chromatographia 67: $275-280$

15. Herrmann AN, Henry RA Importance of controlling mobile phase $\mathrm{pH}$ in reversed phase (RP), Technical bulletin 99.

16. Swartz M, Murphy B (2004) Ultra performance liquid chromatography, Tomorrow's HPLC technology today. Lab Plus International 18: 6-9.

17. Novakova L, Matysova L, Solich P (2006) Advantages of application of UPLC in pharmaceutical analysis. Talanta 68: 908-918.
18. David V Mc Calley (2010) Study of the selectivity, retention mechanisms and performance of alternative silica-based stationary phases for separation of ionized solutes in hydrophilic interaction chromatography, Journal of chromatography 1217: 3408-3417.

19. Jerkovich AD, Mellors JS, Jorgenson JW (2003) The use of Micron-Sized Particles in Ultrahigh-Pressure Liquid Chromatography, LCGC 21: 600-610.

20. Wiczling P, Markuszewski MJ, Kaliszan R (2004) Determination of pKa by pH gradient reversed-phase HPLC. Anal Chem 76: 3069-3077.

21. Snyder LR, Kirkland JJ, Glajch JL (1997) Practical HPLC Method Development (2nd edn) John Wiley \& Sons, Inc., 180.

22. (2000) USFDA Documents-Guidance for Industry: Analytical Procedures and Methods Validation.

23. (1995) ICH Q2 (R1): Validation of Analytical Procedures: Text and MethodologyCurrent Step 4 versions.

24. (1996) ICH Q1 B: Stability testing of new drug substances and products: Current Step 4.

25. (2006) ICH: Impurities in new drug substances Q3A (R2), ICH Harmonised Tripartite Guideline. 